\title{
إدارة المخاطر في السياحة الرياضية فى ظل مواجة (covid.19)
}

\author{
أ.د/عادل محمد عبدالمنعم مكى

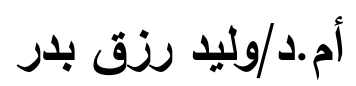 \\ د/محمد حامد فتحى \\ الباحث / محمد عونى طه اسماعيل
}

\section{المقدمـة}

يتميز عالمنا اليوم بتداخل وتسارع حضاري كبير وفي مختلف العلوم والمهن والمعارف، وأصبحنا نتكلم عن عصر الأقتصاد المعرفي والذي نتناول فيه المعلومات كسلع، عصر المعلومات والاتصالات عصر العولمة، وبالتالي هو عصر تطورت فيه وسائل الاتصالات

$$
\text { والتحكم ومعالجة المعلومات وتقارب العالم... }
$$

والمنظمة السياحية تعمل بمناخ يتسم بالحركة والتغير والتتوع الحضاري والكنولوجي والقطاع السياحي أكثر القطاعات تأثراً بالاستقرار والسلام العالمي، ولذلك يتعرض الى العديد من المخاطر والازمات المعقدة داخلياً وخارجياً ولها أسبابها ونتائجها التي تختلف من بلد الى آخر ومن منطقة الى اخرى ومن منظمة الى اخرى بأختلاف طبيعة وخصوصية عمل هذه المنظمــة وعليهـا أن تواجـه كل أنواع المخـاطر سواء كانت مخـاطر سياحية أو مخـاطر اقتصادية وأجتماعية ومخاطر بيئة وصحية بخطة علمية مدروسة لأدارة المخاطر والازمات وتكون في حاجة دائمة للتطور مع مستوى المشكلات التي تواجهها للحفاظ على عناصر 
الطلب والعرض السياحي المتاح والمستقبلي في الدول المختلفة وأن تساهم ايجابياً في حل هذه المشكلات بفكر اداري يتتاسب مع نوع المشكلة أو الازمة من خلال توفر وأعداد كل عناصر التعامل الناجح مع هذه المخاطر والازمات. قام الباحث بـإجراء دراسـة بعنـوان "إدارة المخـاطر في السياحة الرياضية فى ظل مواجـة (covid.19) الرياضي بخصوص ما ترتب علية فيروس كورونا ، ومعرفة كيفية التعامل معهه من خلال المسئولين عن مجال السياحة الرياضية و تطبيق الاجراءات الاحترازية والتصدي لأي كارثة بيئية مماثلة ، وتم تحليل وتفسير ونقد جميع الوثائق التي إستخدمها الباحث وتحديد طرق وأسـاليب الوقايـة من هذا الوبـاء ومعرفة كيفية إنتشـاره ، وأيضـا معرفة الجوانب والتأثثرات المصاحبة لهذا الوبـاء العالمي ومدي الضـرر الذي أودي بحياة الملاين من الأفراد حتي الآن ، وكيفية الحفاظ علي السياحة الرياضية والممارسيين للأنشطة الرياضية بوجه عام ، والحفـاظ علي المنشـأت والممتلكـات وتتعقيم جميـع الأجهـزة والأدوات المسـتخدمة ، وقـام الباحث بوضع تصور مقترح للتأثيرات المصاحبة لوباء فيروس كورونا في مجال السياحة

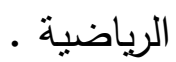

الكلمات الافتتاحية : إدارة المخاطر ، سياحة رياضية ، وباء ، فيروس كورونا . 


\section{مشكنة البحث: -}

في ظل التطور التكنولوجي الهائل ظهرت كارثة بيولوجية باتت تهدد جميع من يعيش على كوكب الأرض وهي ظهور فيروس كورونا ( كوفيد - 9 ـ بr) ، والذي ينتقل من الحيوانات والطيور إلي البشر ، وكان أول ظهور له في الصين ، وخاصة مدينة " ووهان الصينية " ، حيث أصبح عدد المصـابين و الموتي بـالملاين ، وتم عزلها ووضـع سكانها في حجر صحي حتي تم السيطرة علي هذا الخطر بالطرق الصحية السليمة التي أثارت إليها منظمة الصحة العالمية ـ وتم إيقاف المباريات وجميع البطولات سواء كانت محلية أو دولية ، وتم غلق جميع الأندية الرياضية ، والتجمعات البشرية للسيطرة علي هذا الخطر ، وقامت بعض الأندية الرياضية بالعديد من الإجراءات التوعويـة والتتقيفية لتعريف الأعضـاء على كيفية إنتقال الفيروس وطرق الوقاية منه وذلك من خلا المواقع الإلكترونية أو في صفحاتها على مواقع التواصل الإجتماعي، وذلك بسبب المتابعة الكبيرة من كافة شرائح المجتمع حيـث أثنـارت الدراسـات إلى أن فيـروس كورونـا إنضــ لمجموعـة مـن الأوبئـة والأمـراض الخطيرة التي اجتاحت العالم عبر التاريخ، وأثرت بشكل كبير على السياحة و الرياضـة في فترات زمنية مختلفة، ولكن هذا التوقف في عالم الرياضة ليس الأول من نوعه . وكان هناك العديد من الأوبئة التي أثرت على السياحة و الرياضة ـ كالتالي : وباء الكوليرا

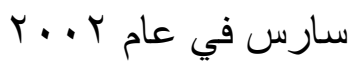




$$
\begin{aligned}
& \text { الأنفلونزا } \\
& \text { الملاريا } \\
& \text { وباء إيبو لا } \\
& \text { زيكا } \\
& \text { الأنفلونزا الإسبانية } \\
& \text { الأنفلونزا الآسيوية } \\
& \text { انفلونز ا الخنازير } \\
& \text { كورونا في عام •r.r. }
\end{aligned}
$$

من هنا تأتي أهمية موضوع بحثنا وخاصـة تطبيقاتتا على السياحة الرياضية وسيتم دراسة

$$
\text { الموضوع من خلال اربع مباحث:-- }
$$

المبحث الاول: مفهوم واهمية السياحة الرياضية ومفهوم ادارة المخاطر وادارة الازمات.

$$
\text { المبحث الثانى: مفهوم (covid.19) والاجراءات الاحترازية ال }
$$

المبحث الثالت: انواع المخاطر والازمات التي تواجه المنظمة السياحية

المبحث الرابع: مقترحات وقواعد لادارة المخاطر والازمات في منظمة السياحية الرياضية

$$
\text { المبحث الاول }
$$

تعريف السياحة الرياضية يعرفها صبرى عبد السميع بأنها هي عملية الانتقال من مكان الإقامة الدائم للفرد إلى مكان أخر داخل أو خارج الدولة لفترة مؤقتة بهدف ممارسة الأنشطة الرياضية المختلفة أو مشاهدتها أو التذريب الرياضى . 
ويعرفها نبيـل الروبسي بأنها هـي التي تتضـمن رحـلات صسيد الأسماك أو ممارسـة أنواع الرياضـات البحربـة وتسـلق الجبـال أو صـيد الطيـور والوحـوش بالإضـافة إلى المباريـات والدورات الرباضية المحلية والإقليمية والدولية .

تعتبر السياحة من أهم مصسادر الدخل لدى الدول المختلفة، لذا تسعى الدول إلى تتمية السياحة داخلها بمختلف أنواعها لجذب المزيد من السياح، وتتتوع أهميتها وتعم فوائدها على الدولة وعلى أهل البلاد وعلى السائحين ونذكر أهميتها فيما يلي: دخول العملة الصـبة إلى البلاد والتي تسـاعد على تتميـة الاقتصـاد الوطني وسد ميزان المدفوعات.

زيادة فرص العمل لدى الثباب وكل الفئات، فحيثما يحل السائح بأي مكان فهو يحتاج إلى المزيد من الخدمات والتي من شأنها توفير فرص العمل المختلفة. تعنبر وسيلة للنبادل النقافي بين الثعوب، وعملية توجيه فكري بنأثز فيها السائح بالطابع التقافي للدولة التي يسـر إليها ويتعرف أكثر سكان البلد الأصلية على ثقافة الثـعوب

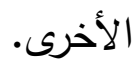
الترفيه والاستمتاع؛ فتعد السياحة وسيلة للحصول على الراحة الجسمية والجسدية عن طريق ممارسة العديد من الأنشطة التي تخخل السرور إلى النفس. 
تعد مرآة حضارية تعكس الوجه الحضاري لشعبها، وتبين الكثير عن عاداته وتقاليده وقيمه الحضارية والتي تنقل انطباعًا عن مدى رقي أهل البلاد.

\section{اولاً: مفهوم ادارة المخاطر :}

أبتداءاً يمكن القول للخطر مدلولات محددة ومختلفة بأختلاف الزاوية التي ينظر

اليها فهناك مـن ينظر للخطر من الزاويـة السـايكولوجية على المستوى الفردي، ويتمثل بالمفاجئات والخسائر التي يمكن ان يتعرض لها سواء أكان ذلك في نتائج أعماله أو شخصه، ويتفاوت تخمين وتقويم آثار هذه المخاطر من شخص لآخر وهذا ما يسمى (بالخطر الذاتي). والـذي يحكمـه عـاملان اساسـيان: التركيــة النفسـية لمتخــ القـرار مـن جانـب وتجربتهـه والمعلومات المتاحة له عن النتائج ومديات الانحراف عنها من جانب آخر. وهناك من ينظر للخطر من الزاوية الفلسفية والتي تقترن بالاخطار على مستوى الافراد والمنشـآت بـالحوادث التصـادفية التي يتكبدون من جرائها خسائر فتتفاوت في شدتها مثل حوادث الطبيعـة كالزلازل والبراكين والعواصف والفيضـانات وتتعت بظواهر قوى الطبيعـة العفويـة، بينمـا وكذللك حـوادث تتعـت بظـواهر المحتمـع مثـل السـرقة والاحتبـال والغـش والتخريب، وغيرها من أسباب سلوكية فردية. 
․ أدارة المخاطر (هي العمليات التي تتضمن على اسلوب للتحكم بالمخاطر بعد تحليلها وتحديدها سواء كانت مخاطر من داخل أو من خارج المنظمة ومهما كان نوعها، مخاطر بيئية أو مخـاطر سياسية أو حتى اقتصـادية أو اجتماعيـة أو مخـاطر ماليـة تواجـه الافراد والمؤسسـات والدولـة عمومـاً، ومحاولـة ادارتها ومعالجتهـا وتجـاوز الخسـارة المترتبـة على حدوث المخاطر في ادنى حدودها والاستفادة من ايجابياتها في الامد البعيد). وان تحليل المخاطر ينقسم الى مرحلتين:-

1 - مرحلة تحليل نوعي والذي يركز على التقدير التعريفي والموضوعي للمخاطر . r- مرحلـة التحليـل الكمـي والـذي يركـز على المنظـور والمـردود التقديري والاحصـائي للمخاطر

\section{أنواع المخاطر}

هناك تقسيمات مختلفة لأنواع المخاطر التي تتعرض لها المؤسسات التي تؤئز بشكل أو بآخر على تحقيق أهدافها ومسـار أعمالها وتعرضـها الى مشـاكل وخسـائر نوعيـة وكيـة متعددة كل حسب طبيعة كل مؤسسة...

فـالبعض يقسم المخـاطر على اسـاس القدرة على التتبؤ بهـا أو صـعوبة التتبؤ والتكهن بحدوثها... وهناك تقسيم المخاطر على اساس البيئة المختلفة كأن تكون مخاطر سياسية أو 
مخاطر اقتصادية ومخاطر قانونية ومخاطر أجتماعية وأخرى أدارية وإعلامية وثقافية ... الخ ثانياً: مفهوم أدارة الازمات

هي مجموع الممارسات التي يمكن تطبيقها عندما ينشأ موقف أو وضع يمثل تغييراً جذرباً في أوضـاع مستقرة تقليديـة وان هذه الممارسـات يتم صياغتها في هيئة خطسة تعتمد في اعدادها على توافر عدد من الخبرات وتبدأ بتحليل وتشخيص أو تشـريح الازمـة وصـولاً لمكوناتها وسماتها وما يتوقع من آثارها وان هذا التحليل لابد وان يتسم بالدقة حتى يكون كل ما بني عليه سليماً يذهب خبراء ادارة الازمات الى انه توجد اربعة نوعيات أو مجموعات رئيسية للأزمات اذا أمكن التعرف عليها أمكن الحيلولة دون وقوعها أو التخفيف من عواقبها أو الاستفادة

$$
\text { أ- أ- البشر عندما يخطئون. }
$$

ب-الاليكترونيات عندما تضطرب وظائفها.

ج- الطبيعة عندما تغضب علينا وعندما نعتدي عليها. 
- الوباء " Epidemic " جمع أوينة وهو " إنتشار مفاجئ وسريع لمرض معين في رقعة جغرافية ما فوق معدلاته المعتادة في ) المنطقة

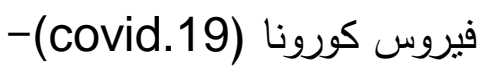

تم تعربف بفيروس ( كورونا ) "تسبة للكلمة اللاتينية (Crown ) ومعناها التاج ، ويعتبر شكل الفيروس تحت الميكروسكوب في شكل التاج ، وهو عبارة عن بعض الفيروسات التي تسبب أعرض شبيهة بنزلات البرد و تصيب كلا من الإنسان والحيوان ، وتتباين الإصـابة ما بين الخفيفة والثديدة ، حيث تؤدي للوفاة ، لأنها تهاجم الجهاز التنفسي ، وتم وضع العديد من المسميات لهذا الفيروس ( كورونـا نوفل ، متلازمـة الثـرق الأوسط التتفسية ، كورونا الجديد ، كورونا الثرق الأوسط )

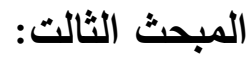

أنـواع المخـاطر والازمـات التي تواجـه المنظمـة السياحية|لرياضية في ادارة الازمـات على المستوى السياحي أنواع المخاطر والازمات السياحية : السياحة كأي نشاط من أنشطة الحياة، تتعرض لمخاطر وأزمات تختلف بشدتها وأسبابها ونتائجها مما يؤثر في السياحة على كافة المستويات عالمياً وأقليمياً وكلياً، وان السياحة 
تتسم بالحساسية ورعة التأثز بالمخاطر الخارجية والازمات التي يتعرض لها عناصر الطلب أو العـرض السـباحي للدولـة، ممـا يعني أن على المنظمـة السـياحية والفندقيـة ان تواجـهـ مخاطر وازمات سياسية واجتماعية وأقتصادية وبيئية معقدة بالاضافة الى سعيها الدائم الى خدمة العملاء واشباع رغباتهم وتحقيق الربحية في آن واحد.

وهذا يتطلب من المنظمات السياحية المختلفة ان تضع خطة متكاملة لأدارة هذه المخاطر والازمات وان تعمل جاهدة ان تجد الحلول المناسبة للتخفيف دن حدة آثار هذه المخاطر والازمـات بعـد دراسـة أسبابها ونتائجها ووضـع البـدائل المناسـبة لأحتواء مـا تركته هـهـ المخـاطر من مشكلات اجتماعيـة وبيئية واقتصـادية، ولأن السـائح هو المحور الذي تدور حوله العملية السياحية ولانه يبحث بالاسـاس عن الامن والطمأنينـة اضـافة الى بحثه عن المتعـة والراحـة واذا أفتقد عامل عدم الاستقرار السياسـي أو الامني أو الاقتصـادي وحتى الصـي تبـرز مشكلة عدم التقـة بكل الجهود التي تبـذل لجذبـه الـى المنطقة أو الدولـة السباحية

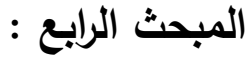

مقترحات وقواعد لأدارة المخاطر والازماتفي المنظمة السياحية وتقدم بعض المقترحات كمنطلبات يجب نوفرها من اجل نشر ثقافة ادارة المخاطر و ادارة الازمات في المنظمات السياحية وعلى المستوى العربي. 


\section{اولاًا المقترحات : سيتم طرحها كخطوتين اساسيتين لتغطية هذا الجانب:-}

الخطوة الاولى: اقامـة مركز لأدارة المخاطر وادارة الازمـات على مستوى الجهة المسؤولة عن القطـاع السـياحي والرياضـى (وزارة سـياحة، وزارة الثـباب والرياضـة ، هيئة... الـخ) وكذلك انشاء قسم أو وحدة متخصصة مسؤولة عن ادارة المخاطر والازمات على مستوى المنظــات السـياحية والرياضـية الفرعيـة لغـرض التتسـيق فيمـا بيـنهم لأتخـاذ التـدابير والاجراءات والقرارات اللازمة اثثاء الخطر أو الازمة.

\section{مهام المركز الاساسية هي: - مي}

1 - رصد الاحداث الطارئة والمخاطر والازمات التي تواجه قطاع السياحة عموماً والمنظمات السياحية والرياضية المتخصصة سواء ازمات من داخل أو من خارج القطاع السياحي، واعداد التقارير والدراسات وتقديم المقترحات وتحديد التوصيات. r- تحقيق الاتصـالات الدائمسة والتتسـيق المستمر مـع مسـؤولي ادارة المخـاطر والازمـات في منظمات الاعمال السياحية المتخصصـة (فنادق وشركات سفر وشركات طيران ... التخ) وكذلك التتسـيق مـع مسـؤولي ادارة الازمـات في الجهـات والـوزارات ذات العلاقـة بالقطـاع السياحي و الرياضى ( وزارة النقل،وزارة البيئة، وزارة التخطيط، وزارة المالية ... هكذا) . ا- تـدعيم قدرة العناصـر البشـرية اللازمـة للعملـ في مجـال ادارة المخـاطر و ادارة الازمـات والتعامل الجيد مع الاحداث الطارئة. 
ومن المهم ان نذكر ان عدم فهم وممارسة مهارة ادارة المخاطر وادارة الازمات بشكل فعال له اسبابه على الاقل من وجهة نظر ادارية وهي بأختصار : 1 - المعلومات الخاطئة والناقصة عن الاحداث والازمات التي تواجه المنظمة. r - التفسير الخاطئ للأمور والاحداث الطارئة والمفاجئة التي تحدث. ب - الضغوط الداخلية والخارجية على اداء المنظمة. ع - ضعف المهارات القيادية في ادارة المنظمة. كون القيادة (علم وفن وذكاء) . ه- الجمود والتكرار في الأداء الاداري حيث لا يقبلون بـالتغير والتطوير والفكري والابداعي والتشربعي. צ- ت تعارض الاهداف بين الادارة والعاملين.

- البحث عن الحلول السهلة مـا يزيد المشكلة بدلاً من بذل الجهود والوقت لحلها ولأنهم لا يحثون عن حلول جذرية بل آنية ووقتية. - أهمية البحث : n - n - n تكمن أهمية البحث في أنه محاولة للتعرف على الأتي : - التعرف على المخاطر المرتبطة بممارسة الأنشطة السياحية الرياضية - معرفة العديد من الظروف المحيطة لهذه المشكلات و الكوراث التي أودت بحياة العديد. - امكانية طبيق الاجرءات الاحترازية الخاصة بالمنشأت السياحية والرباضية 
Risk management In the sports ' إدارة المخاطر في المجال الرياضي "field

"هي عمليـة منهجيـة وتحليليـة لمعرفة إحتمـال أن يكون هناك تهديد للمنشـأة الرياضية أو الأفرد أو العاملين أو الجمهور للخطر ، ويتم من خلال تحديد الإجراءات للحد منها أو تخفيفها أو تقليلها أو تحويل نتائجها . - الوباء " Epidemic " جمع أوبئة وهو " إنتشار مفاجئ وسريع لمرض معين في رقعة جغرافية ما فوق معدلاته المعتادة في ) المنطقة ". - (covid.19) فيروس)

تم تعريف بفيروس ( كورونا ) "تنبة للكلمة اللاتينية (Crown) ومعناها التاج ، ويعتبر شكل الفيروس تحت الميكروسكوب في شكل التاج ، وهو عبارة عن بعض الفيروسات التي تسبب أعرض شبيهة بنزلات البرد و تصيب كلا من الإنسان والحيوان ، وتتباين الإصـابة ما بين الخفيفة والثديدة ، حيث تؤدي للوفاة ، لأنها تهاجم الجهاز التتفسي ، وتم وضـع العديد مـن المسميات لهذا الفيروس ( كورونـا نوفل ، متلازمـة الثـرق الأوسط التتفسية ، كورونا الجديد ، كورونا الثرق الأوسط )" 
زيـادة الـدعم المـادي تحت بنــ الإجـراءات الإحترازيـة، لتوفير أدوات التعقيم والأجهزةة ذلك. 」 المطلوب تنفيذ بروتوكول تعاون بين وزارة الصحة ووزارة الثباب و الرياضة في توفير طاقم طبي دائم لكل مركز

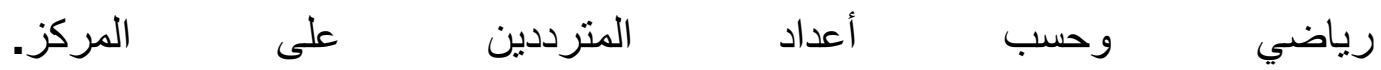
عقد ورش تدرييية للعاملين عن مخاطر الفيروس وكيفية التعامل في حال وجود انتباه الحالات. لأحد اجر اء مسحة الأنف أسبو عياً لجميع المترددين على المركز دون دفع التكلفة. كل القضـايا التي تشـل اهتمـام العـالم قد تفرز مشـاكل ومخاطر عديدة يتأثز بها النظسام السياحي، كون المنظمة السياحية تعمل في جو يتسم بالتتوع والمصاعب والخطر وسرعة

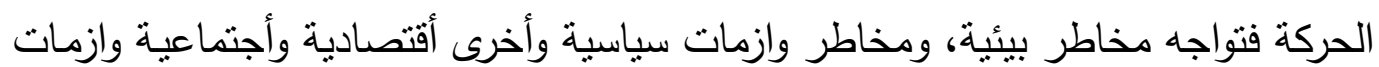
صحية وثقافية وحتى مخاطر تكنولوجية وتتافسية. م ادارة المخاطر وادارة الازمات تقع ضمن مهام الادارة العليا للمنظمـة السياحية اذ لا يمكن تحقيق الاستخدام الامنت لموارد المنظمة وحمايتها بغياب ادارة ناجحة وآمنة مؤهلة لمواجهة المخاطر التي يتعرض لها كل عناصر الطلب أو العرض السياحي للدولة.

O مند تبني اسلوب الادارة غير السليم لمواجهة أزمسة أو خطر تتعرض له دولة سياحية أو

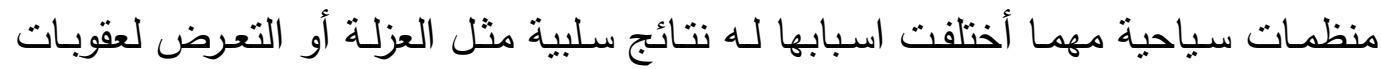
دولية وعدم استقرار سياسي وأقتصادي ونتسويه صورة وسمعة الدولة والمنظمة والفرد وأثره السلبي على اقصاديات العديد من الدول ذات العلاقة مما يخلق ازمات اخرى. 
O هنالك بطء في انتشار الوعي وثقافة المفاهيم واساليب ادارة المخاطر وادارة الازمات على مستوى السياحي العربي بالرغم من تكرار المخاطر والازمات السياحية في العديد من الدول العربية، وأفتقادها الى خطة لأدارة الازمات وتوفر الموارد اللازمـة لتطبيقها ومن أهم هذه الموارد المهارات والخبرات المتخصصة في هذا المجال.

\section{المراجع والمصادر}

ا - د. سليم علي الـوردي، ادارة الخطر والتـأمين، مكتب الـريم للطبع، بغداد،

r - سيد موسس، ادارة الازمات وتطبيقاتها في قطاع السياحة، الكتاب السنوي

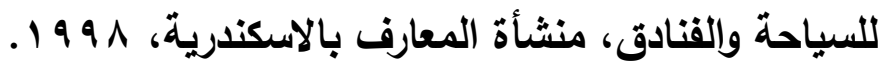
r- د. منى عمر بركات، اداء القطاع السياحي المصري في ظل الازمـات للفترة

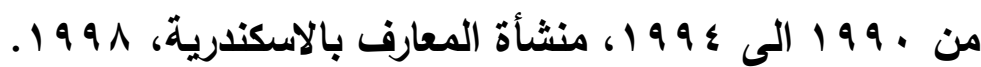

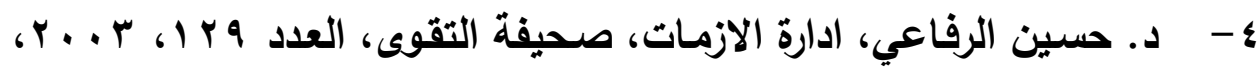
.www.attakwa,net 